\title{
HLA B-27 subtypes in turkish patients with spondyloarthropathy and healthy controls
}

\author{
Fatma Savran Oguz ${ }^{\mathrm{a}, *}$, Lale Ocal ${ }^{\mathrm{b}}$, Ali Sarper Diler ${ }^{\mathrm{a}}$, Hilmi Ozkul ${ }^{\mathrm{a}}$, Faruk Asicioglu ${ }^{\mathrm{a}}$, \\ Esen Kasapoglu ${ }^{\mathrm{b}}$, Gokay Bozkurt ${ }^{\mathrm{c}}$, Meral Konice ${ }^{\mathrm{b}}$ and Mahmut Carin ${ }^{\mathrm{a}}$ \\ ${ }^{a}$ Istanbul University, Istanbul Medical Faculty, Department of Medical Biology Istanbul, Turkey \\ ${ }^{\mathrm{b}}$ Istanbul University, Istanbul Medical School, Department of Internal Medicine, Division of Rheumatology, \\ Istanbul, Turkey \\ ${ }^{\mathrm{c}}$ Trakya University Medical Faculty, Department of Medical Biology. Edirne, Turkey
}

\begin{abstract}
The frequency and the distribution of HLA-B27 subtypes in spondylarthropathy (SpA) patients and controls were investigated in a sample Turkish population. B27 subtyping was performed by PCR-SSP method in two groups: 49 unrelated HLA-B27 positive Turkish patients with the diagnosis of SpA according to the European Spondyloarthropathy Study Group Criteria, and 55 HLA-B27 positive healthy controls. The frequency of HLA-B*27 was $2.6 \%$ in the Turkish population, and $\mathrm{B} * 2705$ was the predominant allele among patients with SpA. The difference was mainly between male patients and male controls The proportion of $\mathrm{B}^{*} 2705$ among B27-positive patients and controls was significantly different $(P=0.02)$. Our study supports other reports from different populations which showed that $\mathrm{B} * 2705$ and $\mathrm{B} * 2702$ were more frequent in Caucasian patients with SpA .
\end{abstract}

Keywords: Spondyloarthropathy, HLA-B27

\section{Introduction}

Ankylosing spondylitis and other seronegative arthritides are characteristically associated with HLA-B27, being present in $90 \%$ of patients. The strong association between HLA-B27 and spondyloarthropathy $(\mathrm{SpA})$ is well-established $[1,2]$ but the mechanism of this association remains unclear. HLA-B27 is an HLA-class I molecule and binds antigenic peptides and presents them to CD8+ cytotoxic T cells (CTL). It has been proposed that presentation of self or bacterial peptides by B27 following infection by arthritogenic bacteria could induce a CTL response. This would be the primary pathogenetic event in these diseases [3] HLA-B27 is a serologic specificity that encompasses

${ }^{*}$ Corresponding author: Dr. Fatma Savran Oguz, Istanbul University, Istanbul Faculty of Medicine, Department of Medical Biology and Bone Marrow Bank, Capa 34390-Istanbul, Turkey. E-mail: oguzsf@usa.net.
25 different alleles that encode 23 different products (proteins): HLA-B*2701 to B*2723 [4]. These alleles are also called subtypes of HLA-B27. The first ten $(\mathrm{B} * 2701$ to $\mathrm{B} * 2710)$ subtypes were studied for disease association. It was shown that the differences in amino acid residues were minor, but B27 subtypes effect the sequence variation on the peptide binding specificity of the molecule. HLA-B27 subtypes differ in their ethnic distribution and in their association with spondylarthropathies (SA). B*2705 and B*2702 are the most frequent subtypes with frequencies of about $90 \%$ and $5-10 \%$ respectively in Caucasians [4]. HLA-B*2704 is the predominant subtype in Asia among Chinese and Japanese [5]. B*2704, *2706 and *2707 have been found exclusively in Asia [6,7]. B*2705 and B*2702 are the most frequent disease-associated subtypes in Caucasians as well as B*2704 and B*2707 in Asia, while B*2706 in Southeast Asia and B*2709 in Sardinia have been reported not to be associated with SA [4,8-10]. The aim of this study was to determine the HLA-B27 subtypes associated with SpA in Turkey. 


\section{Materials and methods}

\subsection{Study group}

Group 1: 49 unrelated HLA-B27 positive Turkish patients with the diagnosis of $\mathrm{SpA}$ according to to the European Spondyloarthropathy Study Group Criteria [11].

Group 2: 55 HLA-B27 positive healthy controls. The control group was randomly selected from 2112 unrelated healthy Turkish bone marrow donors who were screened previously for HLA-B27 serologically and replied to a questioner about rheumatological problems.

\subsection{HLA typing}

DNA was extracted from peripheral blood by a standard method [12]. All patients and controls were typed at the Department of Medical Biology, Istanbul Medical School, which has accreditation to perform clinical typing by European Federation of Immunogenetics. Typing was performed by sequence specific primer (PCRSSP) method using "Olerup SSP - B27 low and high resolution primers" (Genovision, Austria). PCR was performed on a PE 9700 thermal cycle (PE Biosystems, CA). PCR products were visualized in agarose gels under UV illumination following ethidium bromide staining and documented by photography [13]. Statistical evaluation of the difference between proportions was made by Fisher's exact test.

\section{Results}

The frequency of B27 was found to be $2.6 \%$ among 2112 Turkish controls. HLA-B27 alleles in patients and controls are shown in Table 1 and Fig. 1. Patients had an average age of $38.8 \pm 9.8 \mathrm{yr} ; 40$ patients were male and 9 of the patients were female. A total of 27 male and 28 female controls (with B27 specificity) had an average age of $43.0 \pm 10.6$ yr. Five different B27 alleles were found in patients: $\mathrm{B} * 2702, * 2704, * 2705, * 2707$, $* 2708$. P for global distribution difference between the two groups after pooling the rare alleles $(B * 2701$, $\mathrm{B} * 2704$, and $\mathrm{B} * 2708)$ is 0.075 . This slight distortion originates from $\mathrm{B} * 2705$. The proportion of $\mathrm{B} * 2705$ was significantly higher in patients $(P=0.02)$. The difference was mainly between male patients and male controls $(73.2 \%$ vs $48.2 \%, P=0.044)$. In females, the proportion of $* 2705$ was $40.0 \%$ vs $39.3 \%$. The decreased proportion of $\mathrm{B} * 2702$ was also mainly in males (17.1\% vs $37.0 \%, P=0.09$ ). HLA-B27 homozygosity was observed in two patients and one control.

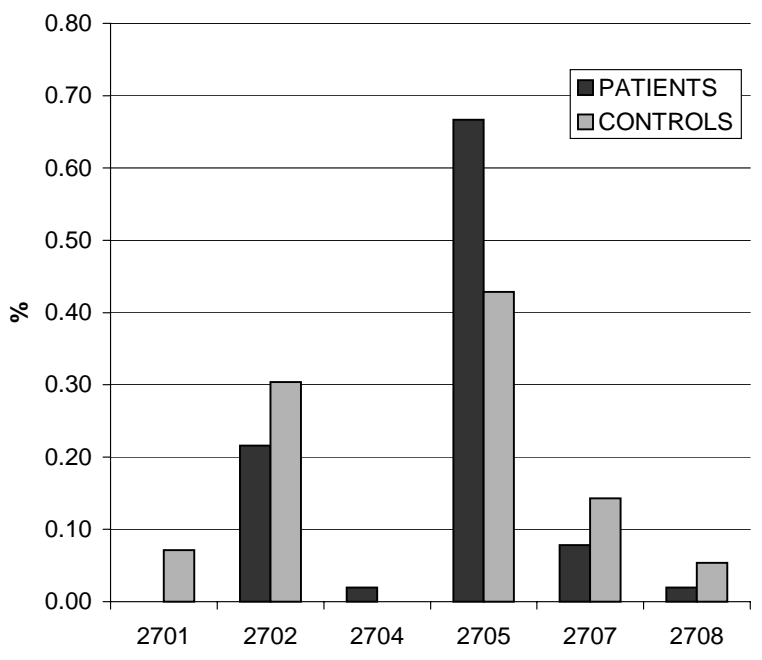

Fig. 1. Schematic presentation of B27 alleles in patients and controls.

\section{Discussion}

The association between HLA class I antigens, B27 and ankylosing spondylitis has been established in 1970s $[14,15]$, and remains to be the strongest HLAdisease association. The frequency of patients with HLA-B27 varies among different SpA ranging from $\sim 50 \%$ in psoriatic and enteropathic arthritis, to $80 \%$ in reactive arthritis, and to over $95 \%$ in primary AS [16]. $\mathrm{B} * 2705, \mathrm{~B} * 2702, \mathrm{~B} * 2704$ and $\mathrm{B} * 2707$ have been reported to be associated with SpA in several studies. The prevalence of HLA-B27 shows a north-south geographic gradient in its distribution. It is highly prevalent in the northern regions of Eurasia and in North American native populations, while its prevalence is low (2-6\%) in some regions of Western and Southern Europe [17,18]. $\quad \mathrm{B} * 2705$ and its relation to $\mathrm{SpA}$ is widespread in nearly all populations except for those of West Africa such as Senegal, Gambia [4,19].

Our study showed 5 subtypes of B27 in SpA patients: B*2702, *2704, *2705, *2707, *2708. HLA-B* 2701, which is a rare subtype found in Caucasoid populations, was not observed in our patients but it was found in $7.14 \%$ the healthy controls. HLA-B*2704 and HLA$B * 2708$ were observed once in patients. HLA-B*2704, which is the predominant allele in Asia among Chinese, Japanese and Thais, is strongly associated with AS and related SpA [20]. HLA-B*2708 is a rare Northern European subtype that was first observed in association 0with AS in Azores Islands [21]. HLA-B*2707 was found in $7.84 \%$ of our patients and $14.3 \%$ in controls. HLA-B*2707 is another disease associated relatively rare subtypes detected in Oriental and Jewish popula- 
Table 1

HLA-B27 alleles in patients and age-matched healthy controls

\begin{tabular}{lcc}
\hline HLA-B*27 & Patient (49 patients, 51 alleles) ${ }^{\mathrm{a}}$ & Control (55 control, 56 alleles) $^{\mathrm{a}}$ \\
\hline 2701 & 0 & 4 \\
& & $(7.14 \%)$ \\
2702 & 11 & 17 \\
& $(21.57 \%)$ & $(30.36 \%)$ \\
2704 & 1 & 0 \\
2705 & $(1.96 \%)$ & 24 \\
& 34 & $(42.86 \%)$ \\
2707 & $(66.67 \%)$ & 8 \\
& 4 & $(14.29 \%)$ \\
2708 & $(7.84 \%)$ & 3 \\
& 1 & $(5.36 \%)$ \\
\hline
\end{tabular}

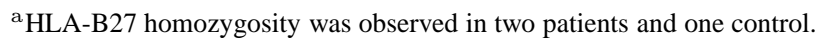

tion and [22]. HLA-B*2705 (90\%) which is the most common subtype in the world was found to be the predominant allele $(66.7 \%)$ among our patients. $\mathrm{B} * 2705$ is virtually the only subtype observed he among the native population of eastern Siberia and North America and is present in about $90 \%$ of the B27 positive individuals of Northern European descent [8]. The subtype is clearly associated with AS and other SpA. HLA-B*2705 was found significantly higher in male patients compared to male controls ( $73.2 \%$ vs $8.2 \%$ ). The high frequency of HLA-B*2705 in male SpA patients is also consistent with previous studies suggesting elevated serum levels of adrenal steroids in male patients with SpA maybe caused by an alteration of 11-beta or 21-hydroxylase gene $[23,24]$. HLA-B*2702 is the second frequent allele in our patients and clearly disease associated. It is present in 4-10\% of B27 positive individuals of Northern Europe, 20\% in Spain and Portugal and around 55\% in Arab and Jewish populations [8,25]. Although the frequency of HLA-B*2702 was higher in the control group than the patients $(30.3 \%$ versus $21.5 \%)$, it was not significant. The frequency of B*2702 in healthy individuals of Turkey is similar to those of Southern Europe and lower than the frequency $55 \%$ in Semitic populations.

\section{Conclusion}

$B * 2705$ was found as the predominant allele in Turkish patients with $\mathrm{SpA}$ and healthy controls. The second frequent allele among patients was $B * 2702$. Yet when compared with the control group, no significant difference was observed. The results support the hypothesis that B*2705 may be the ancestral B27 allele. Turkish population seems to have a genetic admixture which is similar to northern Europe and Mediterranean but different from the far East.

\section{Ackowledgements}

We thank M.Tevfik Dorak for his contribution to the statistical analysis of the data.

\section{References}

[1] A. Svejgaard, P. Platz and L.P. Ryder, HLA and disease suceptibility: clinical implications, Clin Immunol Allergy 4 (1984), 567-580.

[2] B.S. Breur-Vrisendorp, A.J. Dekker-Saeys and P. Ivanyi, Distribution of HLA-B27 subtypes in patients with ankylosing spondylitis: the disease is associated with a common determinant of the various B27 molecules, Ann Rheum Dis 46(5) (1987), 3-356.

[3] C. Lopez-Larea, S. Gonzales and J. Matinez-Borra, The role of HLA-B27 polymorphism and molecular mimicry in spondylarthropathy, Moleculer Medicine Today 4(12) (1998), 540549.

[4] E.J. Ball and M.A. Khan, HLA-B27 polymorphism, Joint Bone Spine 68(5) (2001), 378-382.

[5] C. Lopez-Larrea, K. Sujirachato, N.K. Mehra, P. Chiewsilp, D. Isarangkura, D. Kangkura and U. Kanga et al., HLA-B27 subtypes in Asian patients with anklosing spondylitis:evidence for new associations, Tissue Antigens 45 (1995), 169-176.

[6] S.Y. Choo, P. Antonelli, B. Nisperos, G.T. Nepon and J.A. Hansen, Six variants of HLA-B27 identified by isoelectric focusing, Immunogenetics 23 (1986), 24-29.

[7] S.Y. Choo, L.A. Fan and J.A. Hansen, novel HLA-B27 allele maps B27 allospecifity to the region around position in the alpha 1 domain, J Immunol 147 (1991), 174-180.

[8] M.A. Khan, HLA-B27 and its subtypes in world populations, Curr Opin Rheumatol 7 (1995), 263-269.

[9] T. Hasegawa, Y. Sugahara and Y. Moriyama et al., A new HLA-B27 allele found in a healthy Japanese, Hum Immunol 47 (1996), 8 abst.

[10] S. Gonzales -Roces, C. Barutbar and M. Pena et al., Moleculer analysis of HLA-B27 haplotypes in Caucaids, Frequencies of HLA-B27 -Cw in Jewish and Spanish population, Hum Immunol 41 (1994), 127-134.

[11] M. Dougados, J. Vander Linden and R. Juhlin et al., For the European Spondylarthropathy Study Group. The European SpA Study Group preliminary criteriaa for the classification of SpA, Arthritis Rheum 34 (1991), 1218-1226. 
[12] S. Gustincich, G. Manfiolett, G. Del Sal, C. Schneider and P. Carninci, A fast method for high quality genomic DNA extraction from whole human blood, Bio Techniques 11 (1991), 298-302.

[13] O. Olerup and H. Zetterquist, HLA-DR typing by PCR amplification with sequence primers (PCR-SSP) in 2 hours: An alternative to serological DR typing in clinical practice including donor-recipient matching in cadaveric transplantation, Tissue Antigens 39 (1992), 225-235.

[14] D.A. Brewerton, F.D. Hart, A. Nicholls, M. Caffrey, D.C James and R.D. Sturrock, Anklosing spondylitis and HLAB27, Lancet 28 (1973), 904-907.

[15] L. Schlosstein, P.I. Terasaki, R. Bluestone and C.M. Pearson, High association of an HLA antigen,W27 with anklosing spondylitis, New Engl J Med 288 (1973), 704-706.

[16] M.A. Blanco-Gelaz, A. Lopez-Vazques, S. Garcia-Fernandez, J. Martinez-Borra, S. Gonzales and C. Lopez-Larrea, Genetic variability, moleculer evoluation and geographic diversity of HLA-B27, Hum Immunol 62 (2001), 1042.

[17] J. Braun, m. Bollow, G. Remlinger, U. eggens, M. Rudwaleit, A. Distler and J. Sieper, Prevalance of spondylartropathies in HLA-B27 positive and negative blood donors, Arhritis Rheum 41 (1997), 58-67.

[18] S. Gonzales-Roces, M.V. Alvares and S. Gonzales, HLAB27 polymorphism and worldwide susceptibility to anklosing spondylitis, Tissue Antigens 49 (1997), 116-123.

[19] M. Khan, Prevalance of HLA-B27 in world populations, Curr Opin Rheumatol 7 (1997), 263-269.

[20] C. Lopez-Larra, K. Sujirachato, N.K. Mehra, P. Chiewsilp, D. Isarangkura and U. Kang et al., HLA-B27 subtypes in Asian patients with anklosing spondylitis: evidence for new associations, Tissue Antigens 45 (1995), 169-176.

[21] W.H. Hildebrand, J. Domena, S.Y. Shen, S.G. Marsh, M. Bunce and M.G. Guttridge, The HLA-B7Qui antigen is encoded by a new subtype of HLA-B27 (B*2708), Tissue Antigens 44 (1994), 47-51.

[22] M.A. Blanco-Gelaz, A. Lopez-Vasquez, S. Garcia Fernandez, J. Martinez-Borra and C. Lopez- Larra, Genetic variability, molecular evolution, and geographic diversity of HLA-B27, Hum Immunol 62 (2001), 1042-1050.

[23] L.J. Gooren, E.J. Giltay, D. van Schaardenburg and B.A. Dijkmans, Gonadal and adrenal sex steroids in anklosing spondylitis, Rheum Dis Clin North Am 26(4) ( 2000), 969-987.

[24] D. arniaud, J.P. Mattei, J. Boyer and H. Roux, Sex hormones in spondylarthropaties, A study in 57 patients, Rev rhum Engl Ed 65(1) (1998), 21-26.

[25] A. Fraile, J. Martin, M.A. Lopez-Nevot, L. Mataran and A. Nieto, HLA-B27 subtyping by PCR-RFLP in Spanish patients with anklosing spondylitis, Tissue Antigens 52 (1999), 492 496. 


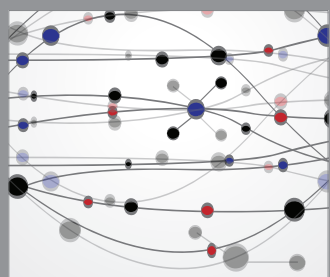

The Scientific World Journal
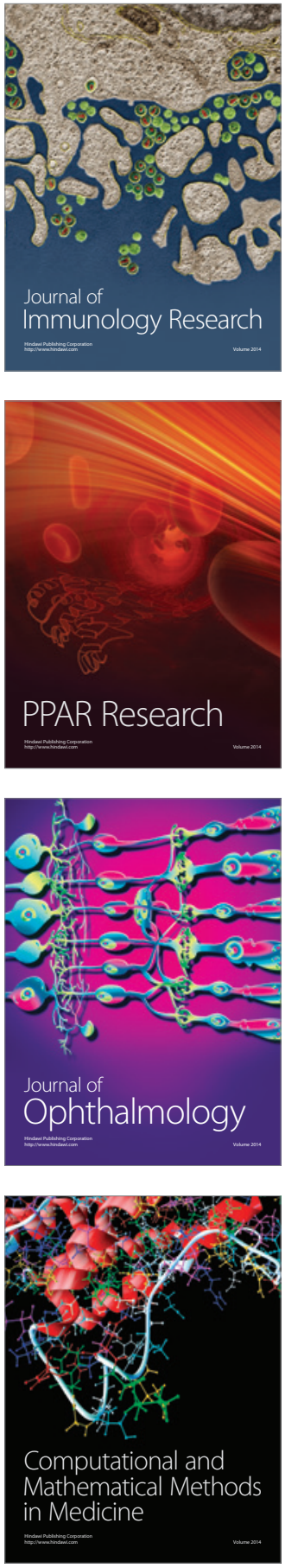

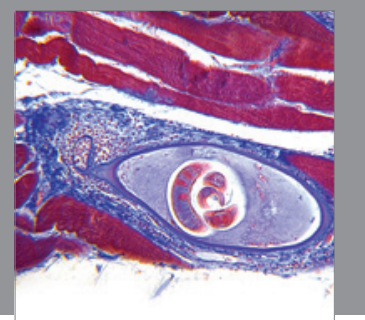

Gastroenterology

Research and Practice
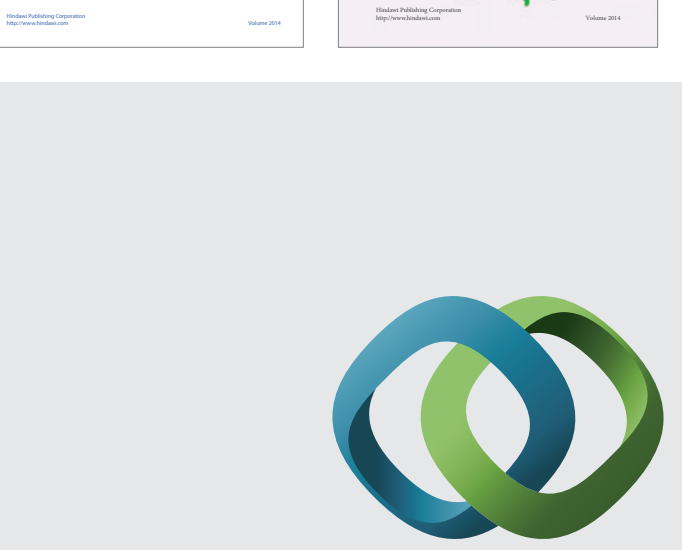

\section{Hindawi}

Submit your manuscripts at

http://www.hindawi.com
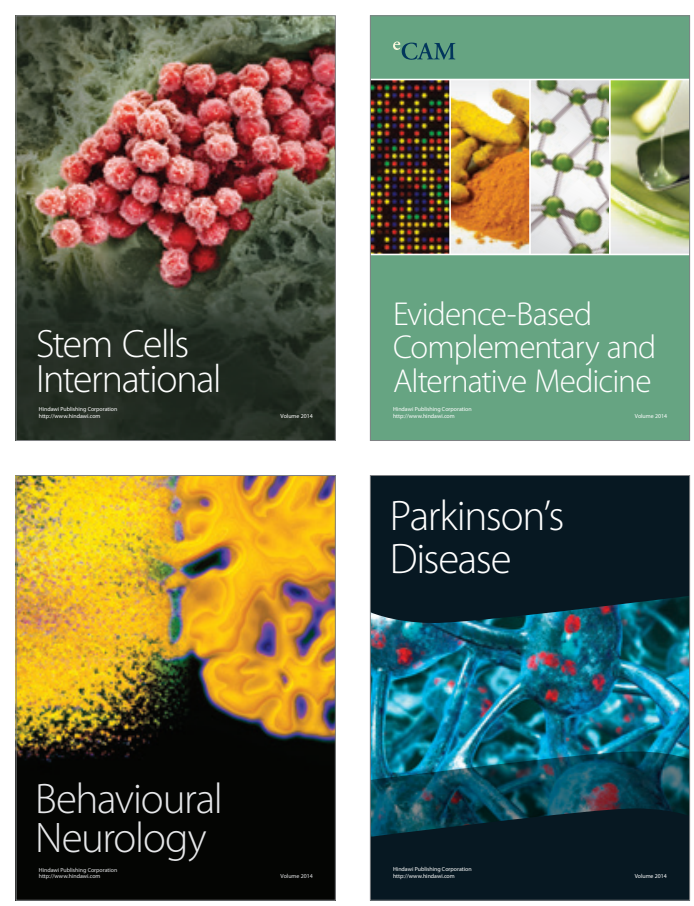

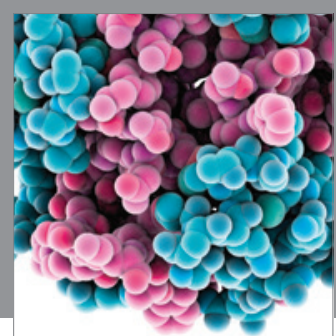

Journal of
Diabetes Research

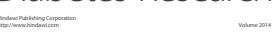

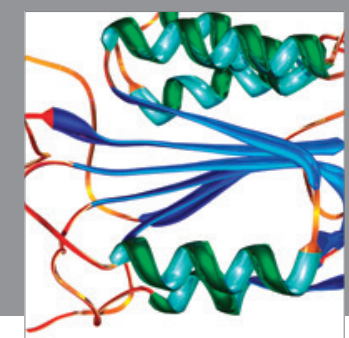

Disease Markers
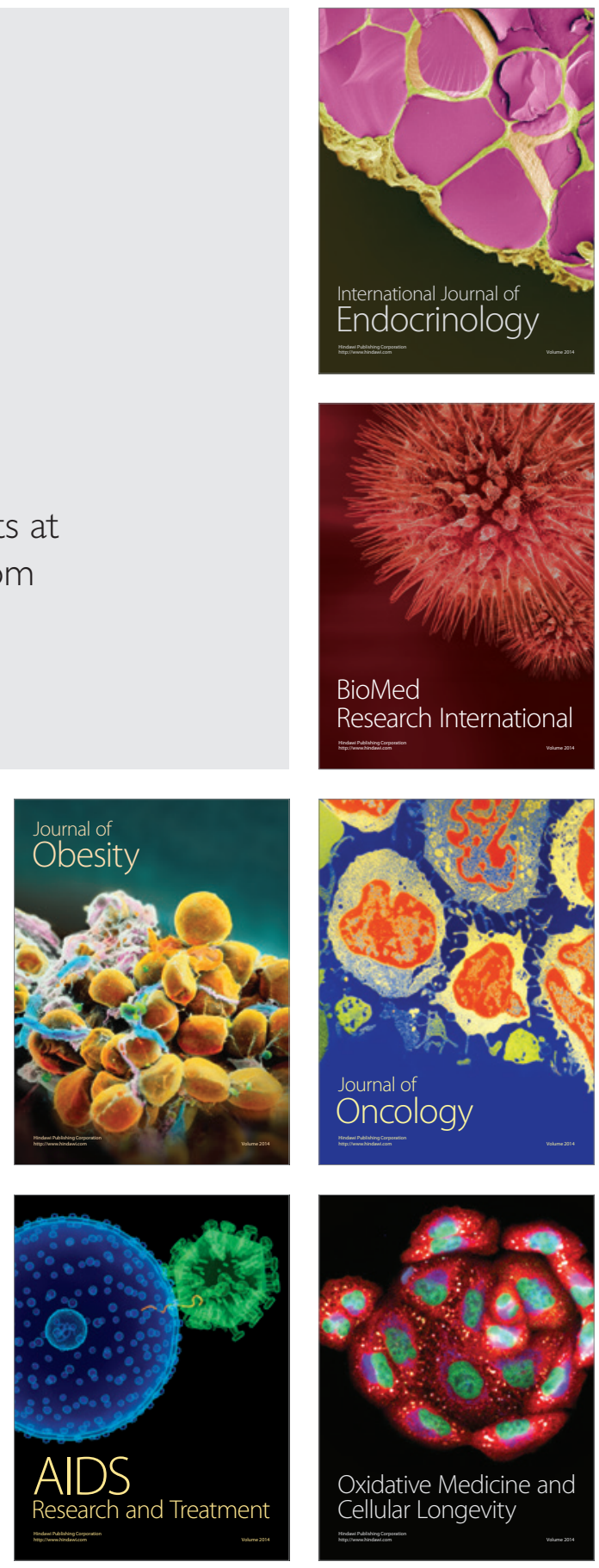